\title{
Effective method for the detection of
} piroxicam in human plasma using HPLC. Braz Oral Res. 2016;30(1):e58. DOI: 10.1590/1807-3107BOR-2016.vol30.0058

\author{
Author's affiliation \\ Where is read: Vera Lúcia LANCHOTE(a) \\ It should read: Vera Lúcia LANCHOTE(b)
}

Affiliation:

Where is read: (b) Universidade de São Paulo - USP, School of Pharmaceutical Sciences of Ribeirão Preto, Laboratory Specialist, Department of Clinical, Toxicologic and Bromatologic Analyses, Ribeirão Preto, SP, Brazil.

It should read: (b) Universidade de São Paulo - USP, School of Pharmaceutical Sciences of Ribeirão Preto, Department of Clinical, Toxicologic and Bromatologic Analyses, Ribeirão Preto, SP, Brazil.

DOI: 10.1590/1807-3107BOR-2016.vol30.0058erratum 